\title{
Editorial
}

\section{Quando não conseguimos mais sonhar acordados}

When we can no longer daydream

Sérgio de Gouvêa Franco*

Quando Freud publicou seu monumental $A$ interpretação de sonhos no finalzinho do século XIX, mais do que apresentar um profundo estudo sobre os sonhos, ele apresentou uma concepção acerca do humano. A energia do sonho vem do desejo; sem desejo não há sonho. É o desejo enraizado na biografia e escondido no inconsciente que oferece o combustível para a formação dos sonhos. Freud compara a um empreendimento econômico: sem capital não há empreendimento; sem desejo nada se move. Claro que o sonho é mais que desejo. Ele expressa os sentimentos e as circunstâncias de quem sonha, expressa igualmente anseios do sistema Pré-Consciente/Consciente. Mas a hipótese que está sustentando Freud com esse livro, que emerge de seus estudos sobre o sonho, é que o ser humano é ser do desejo. Wunsch no alemão de Freud. O humano é animal desejante. O sonho é uma realização disfarçada de um desejo infantil. O desejo expressa um anseio em direção a um devir de prazer, que se assenta em uma

*Fundação Escola de Comércio Álvares Penteado - FECAP (São Paulo, SP, Br). 
experiência real ou fantasiada de um prazer na origem da vida, possivelmente junto ao seio materno. Uma concepção não linear de tempo se manifesta, alinhavando passado, presente e futuro ou futuro, presente e passado.

No curso de seu trabalho intelectual, Freud foi mostrando que o desejo está presente na vida consciente, nos atos falhos, nos chistes, nos sintomas. De modo mais ou menos evidente. Na segunda tópica, ele deixou claro que toda formação da cultura está assentada sobre o desejo. É certo que o desejo se manifesta na vida da vigília de um modo bem diferente do modo como se manifesta nos sonhos. No inconsciente reina o processo primário; na vida desperta, o processo secundário avança. De modo que o desejo está mais contido e se apresenta na forma de uma solução de compromisso. A cultura frustra parcialmente o desejo, mas também o expressa e o veicula. Quem sabe possamos dizer que a cultura é o grande empreendimento humano para exorcizar a morte, para levar adiante o desejo de viver para sempre. Sonhamos dormindo e sonhamos acordados.

Já em $A$ interpretação de sonhos, Freud nos fala dos sonhos de angústia. Mais tarde, em "Além do princípio de prazer", de 1920, ele fala dos sonhos traumáticos. Nos sonhos de angústia, a censura não cumpre perfeitamente o seu trabalho e um desejo infantil insuportável para o ego aparece, acordando o sonhador. A angústia evita que algo mais grave aconteça, a saber, a realização onírica de um desejo que o ego não aceita nem suporta. Nos sonhos traumáticos, o desejo não pode se apresentar claramente. Estamos em um além, ou em um aquém, do princípio do prazer. Há um colapso da função onírica. Alguém poderia dizer que já nos sonhos de angústia, o aparelho psíquico tem dificuldade de cumprir o seu papel. Nos sonhos traumáticos isso é evidente. Esse fracasso da função onírica nos aponta para uma deficiência, para uma dificuldade para pensar e simbolizar o que se está vivendo. O fracasso da função onírica é, na verdade, um fracasso da capacidade de simbolizar, de processar a vida. As consequências nós conhecemos: as manifestações somáticas, as adições e as atuações. Nem é necessário dizer que tudo isto está presente entre nós.

A recuperação da função onírica, a recuperação da capacidade de pensar e de simbolizar tem impacto para o indivíduo. Mas não apenas para o indivíduo. Há também uma dimensão social e política. Se o indivíduo não consegue pensar o que se passa com ele, o que aconteceria com uma sociedade composta por indivíduos que perderam a capacidade de pensar? Ou que tem capacidade de pensar reduzida? Pode ser que as deficiências de simbolização de nosso tempo tenham a ver não apenas com deficiências 


\section{EDITORIAL}

estruturais e intrapsíquicas. Pode ser que o modo como se dão os laços sociais estejam favorecendo a diminuição da capacidade simbolizante. A desilusão política pode estar sendo vivida de modo traumático e melancólico. A coragem que emerge da confiança pode ter perdido a sua força.

Há indicações, aqui e acolá, de que a linha que separa o campo do possível do campo do impossível não é fixa. A linha é móvel. O que pensamos ser possível fazer como indivíduos e como sociedade, em determinado momento da história, tem a ver com a confiança que sustentamos em relação ao que está posto. Uma consciência prisioneira, amedrontada, não pode mudar nada. Neste sentido, a saída do imobilismo e da perplexidade atuais teria a ver com a recuperação da capacidade de sonhar, desejar e imaginar novas formas de vivências pessoais e sociais. Winnicott, em Brincar e realidade, faz uma distinção, por um lado, de um fantasiar impotente, delirante e estéril e, por outro, de uma investigação imaginativa das possibilidades, que ele chama de um legítimo sonhar acordado. Se a capacidade de sonhar dormindo colapsa, pode ser que ela colapse também na vida desperta. Talvez seja a hora de trabalhar no plano clínico e no plano social para restaurar a função onírica prejudicada, trabalhar para restaurar o sonho dormindo e o sonho acordado. De modo que seja possível pessoal e socialmente, lançarmos outra vez nossas redes ao mar.

Talvez esse movimento da função onírica, em três passos - afirmada, em colapso e restaurada - possa ter um paralelismo não apenas com a vida nacional, mas, também, com nossa Associação Universitária de Pesquisa em Psicopatologia Fundamental. Refazendo, assim, nossa capacidade de pensar e agir após a morte do fundador Dr. Manoel Tosta Berlinck. Redes ao mar.

\section{Referências}

Bloch, E. (2005-2006). Princípio esperança. Rio de Janeiro, RJ: Contraponto/Ed. UERJ.

Freud, S. (1969). A interpretação de sonhos. In: Edição Standard Brasileira das Obras Psicológicas Completas de Sigmund Freud (v, IV e V). Rio de Janeiro, RJ: Imago. (Trabalho original publicado em 1900).

Freud, S. (1969a). Além do princípio de prazer. In: Edição Standard Brasileira das Obras Psicológicas Completas de Sigmund Freud (v, VXIII). Rio de Janeiro, RJ: Imago. (Trabalho original publicado em 1920).

Ricoeur, P. (1977). Da interpretação: ensaio sobre Freud. Rio de Janeiro, RJ: Imago. 
Winnicott, D. (1975). O brincar e a realidade. Rio de Janeiro, RJ: Imago.

Citação/Citation: Franco, S. G. (2017, dezembro). Editorial. Quando não conseguimos mais sonhar acordados. Revista Latinoamericana de Psicopatologia Fundamental, 20(4), 637-640. http://dx.doi.org/10.1590/1415-4714.2017v20n4p637.1

Editores do artigo/Editors: Profa. Dra. Ana Maria Rudge e Profa. Dra. Sonia Leite

Recebido/Received: 10.10.2017/ 10.10.2017 Aceito/Accepted: 19.10.2017 / 10.19.2017

Copyright: (C) 2009 Associação Universitária de Pesquisa em Psicopatologia Fundamental/ University Association for Research in Fundamental Psychopathology. Este é um artigo de livre acesso, que permite uso irrestrito, distribuição e reprodução em qualquer meio, desde que o autor e a fonte sejam citados / This is an open-access article, which permits unrestricted use, distribution, and reproduction in any medium, provided the original authors and sources are credited.

\section{Sérgio de Gouvêa Franco}

Psicanalista; Doutor pela Universidade Estadual de Campinas - Unicamp (Campinas, São Paulo, SP, Br); Pós-doutor em Psicologia Clínica pela Pontifícia Universidade Católica de São Paulo - PUC-SP (São Paulo, SP, Br); Membro do Departamento de Psicanálise do Instituto Sedes Sapientiae (São Paulo, SP, Br), onde fez formação em Psicanálise; Presidente da Associação Universitária de Pesquisa em Psicopatologia Fundamental AUPPF (São Paulo, SP, Br) período de 2016-2018; Professor do Curso de Formação em Psicanálise do CEP (São Paulo, SP, Br) e professor da Pós-Graduação na Fundação Escola de Comércio Álvares Penteado - FECAP (São Paulo, SP, Br), onde foi Reitor no período de 2006 a 2010. Autor do livro Mandrágoras, clínica psicanalítica: Freud e Winnicott (São Paulo: Primavera Editorial), em parceria com Manoel Tosta Berlinck e Karin Wondracek, entre outras publicações no país e exterior.

Av. 11 de junho, 1070/804 - Vila Clementino

04041-004 São Paulo, SP/Br

Telefax: 5511 5574-1175

sg-franco@uol.com.br

This is an open-access article, which permits unrestricted use, distribution, and reproduction in any medium for non-commercial purposes provided the original authors and sources are credited. 